\title{
Design, Development, and Optimization of Sterculia Gum-Based Tablet Coated with Chitosan/Eudragit RLPO Mixed Blend Polymers for Possible Colonic Drug Delivery
}

\author{
Bipul Nath, ${ }^{1,2}$ and Lila Kanta Nath ${ }^{2}$ \\ ${ }^{1}$ Department of Pharmaceutical Sciences, Girijananda Chowdhury Institute of Pharmaceutical Sciences (GIPS), \\ Azara, Assam, Guwahati 781001, India \\ ${ }^{2}$ Girijananda Chowdhury Institute of Pharmaceutical Sciences (GIPS) Affiliated to Gauhati University, \\ Azara, Assam, Guwahati 781017, India
}

Correspondence should be addressed to Bipul Nath; bipulnath@gmail.com

Received 15 August 2012; Revised 5 October 2012; Accepted 9 October 2012

Academic Editor: Antonio Ruiz Medina

Copyright (C) 2013 B. Nath and L. K. Nath. This is an open access article distributed under the Creative Commons Attribution License, which permits unrestricted use, distribution, and reproduction in any medium, provided the original work is properly cited.

\begin{abstract}
The purpose of this study is to explore the possible applicability of Sterculia urens gum as a novel carrier for colonic delivery system of a sparingly soluble drug, azathioprine. The study involves designing a microflora triggered colon-targeted drug delivery system (MCDDS) which consists of a central polysaccharide core and is coated to different film thicknesses with blends of chitosan/Eudragit RLPO, and is overcoated with Eudragit L00 to provide acid and intestinal resistance. The microflora degradation property of gum was investigated in rat caecal medium. Drug release study in simulated colonic fluid revealed that swelling force of the gum could concurrently drive the drug out of the polysaccharide core due to the rupture of the chitosan/Eudargit coating in microfloraactivated environment. Chitosan in the mixed film coat was found to be degraded by enzymatic action of the microflora in the colon. Release kinetic data revealed that the optimized MCDDS was fitted well into first-order model, and apparent lag time was found to be 6 hours, followed by Higuchi release kinetics. In vivo study in rabbits shows delayed $T_{\max }$, prolonged absorption time, decreased $\mathrm{C}_{\max }$, and absorption rate constant $(\mathrm{Ka})$, indicating a reduced systemic toxicity of the drug as compared to other dosage forms.
\end{abstract}

\section{Introduction}

In the recent times, colon-specific technologies have utilized single or combination of the following primary approaches, with varying degrees of success: (1) pH-dependent systems, (2) time-dependent systems, (3) prodrugs, and (4) colonic microflora-activated systems [1,2]. Among the different approaches to achieve colon specific drug delivery system, the use of polymers specifically degraded by colonic bacterial enzymes (such as $\beta$-glucoronidase, $\beta$-xylosidase, $\beta$ galactosidase, and azoreductase) holds promise. Microbially activated delivery systems for colon targeting are being developed to exploit the potential of the specific nature of diverse and luxuriant microbiota associated with the colon compared to other parts of the gastrointestinal (GI) tract. These colonic microbiotas produce a large number of hydrolytic and reductive enzymes which can potentially be utilized for colonic delivery $[1,2]$. Most of these systems are based on the fact that anaerobic bacteria in the colon are able to recognize the various substrates and degrade them with their enzymes. Natural gums are often preferred to synthetic materials due to their low-toxicity, low-cost, and easy availability. A number of colon-targeted delivery systems based both on combination of $\mathrm{pH}$, polysaccharides and biodegradable polymers have been designed and developed by various research groups for successful delivery of drugs to the colonic region $[3,4]$. Sterculia gum has not yet been used as drug carrier specifically to the colon. It is insoluble in water, hydrates quickly, and swells into a homogenious hydrogel consistency or mass which pose difficulty for its use as polysaccharide coat [5]. But, it seemed to be an interesting polymer for the preparation of hydrophilic matrix tablets $[6$, 
7]. However, sterculia gum in the form of hydrophilic matrix cannot protect the drug from being released in stomach and small intestine. Besides, sterculia gum is expected to retard drug release due to its higher swelling index, and at the same time its degradation by the colonic microflora would make it ideal to deliver drugs in the colon. The property of higher swelling index would provide greater surface area for more bacterial enzymatic attack. This property of the gum could be used to produce hydrostatic pressure in the design of microflora triggered colon targeted drug delivery system (MCDDS). In this system, the hydrostatic force is produced by osmotic agents and polymer swelling which concurrently drives the drug out of the system through the pores created by the pore-forming agent in the inner coating after exposure of the system to the colonic fluid $[8,9]$. In addition, eudragit RLPO polymer has been reported to increase the permeability to colonic fluid due to the presence of higher number of quaternary ammonium groups.

Hence, the objectives of present investigation was to design MCDDS based on swelling property of sterculia gum and to study the influence of different independent variables on dependent variables. The design of MCDDS comprises of an osmotic tablet core containing model drug azathioprine (AZA), sterculia gum as binder, and other excipients; an inner semipermeable coating which is over coated with enteric layer to provide acid and intestinal resistance. The study includes the optimization of chitosan/eudragit RLPO mixed film coating for colonic delivery of polysaccharide core and to investigate the effects of the polymer blend ratio, concentration of pore former in the coat and coating thickness on the resulting drug release and to propose the drug release mechanism of the system. The innermost layer of chitosan/eudragit RLPO provides desired intestinal resistance, but controlling drug release in the colon [10]. Eudragit L100 was deposited in order to protect the delivery system from the gastric acidic conditions. A multilayered approach was selected, since such a dosage form was less likely to undergo dose dumping, and also, it may facilitate the spreading of the drug over the inflamed regions of the colonic lumen. The feasibility of the novel MCDDS was studied using AZA as a model anti-inflammatory drug via in vitro evaluation of drug release characteristics and in vivo assessment of pharmacokinetics in rabbits $[11,12]$.

\section{Materials and Methods}

2.1. Materials. AZA was obtained as gift samples from RPG Life Sciences Pvt. Ltd, India. Commercially available sterculia gum powder was obtained from Krystal Colloids, Mumbai. Citric acid monohydrate, anhydrous lactose, magnesium stearate, disodium hydrogen phosphate $\left(\mathrm{Na}_{2} \mathrm{HPO}_{4}\right)$, and potassium dihydrogen phosphate $\mathrm{KH}_{2} \mathrm{PO}_{4}$ were purchased from Loba chemie, Mumbai, India. Eudragit RLPO and Eudragit L100 were obtained from Rhom Pharm, Darmstadt, Germany). PEG 400, acetone, isopropyl alcohol and 95\% ethanol, triethyl citrate, and talc were purchased from Rankem, Mumbai. $\beta$-glucosidase was obtained from Sigma
TABLE 1: Composition of the swellable core tablet.

\begin{tabular}{lc}
\hline Ingredients & Weight in \% w/w \\
\hline Azathioprine & 20.83 \\
Sterculia gum & 35.83 \\
Citric acid & 15.15 \\
Anhydrous lactose & 26.19 \\
Magnesium stearate & 2.0 \\
\hline Total & 100 \\
\hline
\end{tabular}

Chemical Co, Bangalore, India. All other used chemicals were of analytical grade.

2.2. Microflora Degradation Studies of Sterculia Gum in Rat Caecal Contents. Microflora degradation studies of sterculia gum were conducted in phosphate buffer solution (PBS) $\mathrm{pH}$ 7.4 containing rat caecal content $[13,14]$. Caecal contents were collected from male Wistar rats weighing 250-300 g each. The caecal contents were dispersed in PBS under anaerobic environment (bubbled with $\mathrm{CO}_{2}$ gas), and the concentration of the caecal contents was adjusted to 4.0, 8.0 and $12.0 \%(\mathrm{w} / \mathrm{v})$ in the PBS. Finely grounded sterculia gum powder $100 \mathrm{mg}$ was added into $10 \mathrm{~mL}$ of caecal PBS and incubated at $37^{\circ} \mathrm{C}$ under anaerobic condition. The $\mathrm{pH}$ of caecal PBS was measured at $2 \mathrm{~h}$ interval up to $8 \mathrm{~h}$ using a $\mathrm{pH}$ meter.

2.3. Preparation of Swellable Core Tablets. The detail composition of the core tablet is presented in Table 1 . The core tablets of AZA having an average weight of $240 \pm 5 \mathrm{mg}$ were prepared by direct compression using a single stroke tablet punching machine fitted with $8 \mathrm{~mm}$ round standard concave punches. Sterculia gum was used as binder cum hydrophilic matrix former, anhydrous lactose as diluents, citric acid as $\mathrm{pH}$ regulating excipient, and magnesium stearate as lubricant $[15,16]$.

\subsection{Preparation of Chitosan-Eudragit RLPO Coating Dis-} persions. In the initial trial, a coating solution of eudragit RLPO $(10 \% \mathrm{w} / \mathrm{v})$ in propan-2-ol: acetone $(60: 40)$ containing $15 \% \mathrm{w} / \mathrm{w}$ or $25 \% \mathrm{w} / \mathrm{w}$ concentration of chitosan was used to apply a semipermeable coat on the core tablet. PEG 400 ( $25 \%$ of total coating materials) was added to improve the physicomechanical property of eudragit RLPO film. The coating conditions were as follows: stainless steel pan, $200 \mathrm{~mm}$ diameter, four baffled, rate of rotation of the coating pan; $40 \mathrm{rpm}$, nozzle diameter of spray gun; $1 \mathrm{~mm}$, spray rate; $5 \mathrm{~mL} / \mathrm{min}$, spray pressure; $2 \mathrm{Bar}$, drying temperature; $40^{\circ} \mathrm{C}$ [17]. After coating, the tablets were dried for 8 hours at $35-40^{\circ} \mathrm{C}$ in order to remove the residual solvent.

\subsection{Experimental Design for Coating Formulations. A full $3^{2}$} factorial design was used for optimization of coating solutions $[18,19]$. The concentration of chitosan was selected by using central composite design (CCD) under design expert software (version 8.0). The studied factors (independent variables) were concentration of pore former, chitosan $\left(X_{1}\right)$, 
and weight gain in coating thickness, eudragit RLPO $\left(X_{2}\right)$. The dependent variables selected for the study include lag time for drug release up to $2 \%$ in SCF $\left(Y_{1}\right)$ and percent drug release in 12 hours $\left(Y_{2}\right)$ and 18 hours $\left(Y_{3}\right)$.

2.6. Physical Evaluation of the Coated Tablets under Factorial Design. The thickness, hardness, drug content uniformity and weight uniformity were determined in a similar manner as stated for conventional oral tablets in the accredited pharmacopoeia.

2.7. In Vitro Dissolution Study of Chitosan-Eudragit RLPO Coated Tablets. In order to optimize the coating formula containing different concentration of pore former, in vitro dissolution studies of core coated with different proportions of coating materials were carried out in USP dissolution test apparatus, Type I (Campbell Electronics, Mumbai, India) in $900 \mathrm{~mL}$ of simulated colonic fluid (SCF is phosphate buffer medium, $\mathrm{pH} 7.4$ containing rat caecal content $4 \%$ and $\beta$-glucosidase $2 \% \mathrm{w} / \mathrm{v}$ ) for 18 hours under anaerobic environment $[20,21]$. $\beta$-glucosidase was added to degrade chitosan, in colonic environmental conditions. Aliquots of dissolution fluid were analyzed at specified time intervals to determine the release of AZA by UV-visible spectrophotometer at wavelength of $281 \mathrm{~nm}$.

\subsection{Statistical Analysis of Data and Coating Optimization.} The response values (lag time in hour, \% drug release in 12 hour and 18 hour resp.) of coated tablets based on $3^{2}$ factorial design were subjected to analysis by response surface reduced quadratic model with the help of Design Expert software (Version 8.0). Statistical validity of the polynomial was established on the basis of ANOVA provision in the design expert software, and significant terms $(P<0.05)$ were chosen for final equations $[18,22]$. Response surface plots and $3 \mathrm{D}$ contour plots were constructed using the output files generated.

2.9. Enteric Coating of Chitosan-Eudragit RLPO Coated Tablets with Eudragit L100. Eudragit L100, which dissolves above $\mathrm{pH}$ 6.0, was selected for enteric coating [23]. The optimized chitosan-eudragit RLPO coated tablets were further over coated with enteric coating using $10 \% \mathrm{w} / \mathrm{v}$ of eudragit L100 in 95\% ethanol. The total weight gain of eudragit L100 coating was 10\% w/w. Eudragit L100 was dissolved in 95\% ethanol under high stirring condition until a clear solution was obtained. Triethyl citrate (TEC), 10\% w/w of total dry polymer was added as plasticizer and talc $(1.5 \% \mathrm{w} / \mathrm{w}$ of dry polymer) as a glidant. The coating conditions were same employed under semipermeable coating.

2.10. Kinetic Evaluation of Drug Release Data and Stability Studies. Dissolution data of the optimized formulation was fitted to various mathematical models in order to describe the mechanism of drug release [24, 25]. The corelation coefficient $\left(r^{2}\right)$ was taken as the criteria for choosing the most appropriate model. The selected formulations were tested for a period of 8 weeks at different storage conditions of $25^{\circ} \mathrm{C}$ and $40^{\circ} \mathrm{C}$ with $60 \% \mathrm{RH}$ and $75 \% \mathrm{RH}$, to evaluate their drug content, hardness, and in vitro dissolution rate [26].

2.11. HPLC Assay. In the present method, the plasma 6mercaptopurine (6-MP) rather than AZA concentration was measured because after oral administration AZA is quickly converted into its active metabolite 6-MP. The 6-MP concentration in plasma was determined according to the HPLC method reported by Shao-Jun et al. [27]. The HPLC system consisted of a Rheodyne Isocratic pump (Model-LC-10, Shimadzu Corp., Kyoto, Japan) a model 2250 pump (Bischoff, Germany), and a UV detector (Model-SPD, Shimadzu Corp., Kyoto, Japan) set at a wavelength of $325 \mathrm{~nm}\left(\lambda_{\max }\right)$. The samples were chromatographed on a reverse phase Hypersil ODS C18 column $(5 \mu \mathrm{m}, 25 \mathrm{~cm} \times 4.6 \mathrm{~mm}$ i.d., Thermo Electron Company, Bellefonte, North America) protected with a guard column $(40 \times 4 \mathrm{~mm})$ packed with the same material. The mobile phase was consisting of 80 parts of $0.01 \mathrm{M} \mathrm{KH}_{2} \mathrm{PO}_{4}$ and 20 parts of Acetonitrile $(80: 20, \mathrm{v} / \mathrm{v}, \mathrm{pH} 4.5)$. It was pumped at a flow rate of $1 \mathrm{~mL} / \mathrm{min}$ for the run time of 10 min under the experimental conditions with an injection volume of $20 \mu \mathrm{L}[28,29]$. The column was thermostated at an ambient temperature $30^{\circ} \pm 2^{\circ} \mathrm{C}$ throughout the study. The effluent was monitored with the UV-Visible detector at $325 \mathrm{~nm}$. Metronidazole was used as an internal standard (IS).

2.12. In Vivo Study in Rabbits. The pharmacokinetics of marketed tablet (MKT), enteric coated tablet (EC), and MCDDS of AZA were assessed and compared in rabbits in a randomized, two-period crossover study. The washout period between administrations was one week. Six rabbits each weighing from 1.5 to $2.0 \mathrm{~kg}$ were used in this study. The rabbits were fed standard laboratory chew diet with water and fasted overnight before the experiments. The animals used in the experiments received care in compliance with the "Principles of Laboratory Animal Care" and "Guide for the Care and Use of Laboratory Animals." Experiments followed an approved protocol from Department of Pharmaceutical Sciences, Dibrugarh University Institutional Animal Ethical Committee.

The MKT, EC, and MCDDS (containing $50 \mathrm{mg} / \mathrm{Kg}$ of drug) were orally administered in rabbits. At time intervals, two milliliters of blood samples were collected from marginal ear vein into heparinized tubes and centrifuged at $5000 \mathrm{rpm}$ for $15 \mathrm{~min}$ at $4^{\circ} \mathrm{C}$ to separate plasma. The plasma samples, $0.2 \mathrm{~mL}$, were deproteinized with $2.0 \mathrm{~mL}$ of methanol and acetonitrile mixture $(1: 1, \mathrm{v} / \mathrm{v})$, vortexed for $5 \mathrm{~min}$, centrifuged at $6000 \mathrm{rpm}$ for $15 \mathrm{~min}$, and supernatants were collected. The supernatants were evaporated to dryness under a gentle nitrogen stream at $40^{\circ} \mathrm{C}$. The residues were reconstituted in $200 \mu \mathrm{L}$ of mobile phase, and then $20 \mu \mathrm{L}$ of each solution was injected into the HPLC column for analysis of the drug in vivo. Blood sampling time points were $0,1,2,3,4,5,6,7,8$, $9,10,12,14,16,18,20,22$, and 24 hours after administration of the EC and MCDDS. For the MKT tablet of AZA, blood samples $(2.0 \mathrm{~mL})$ were drawn at $0,0.5,1,2,4,5,6$, and $24 \mathrm{~h}$ after administration. The drug concentration of plasma 


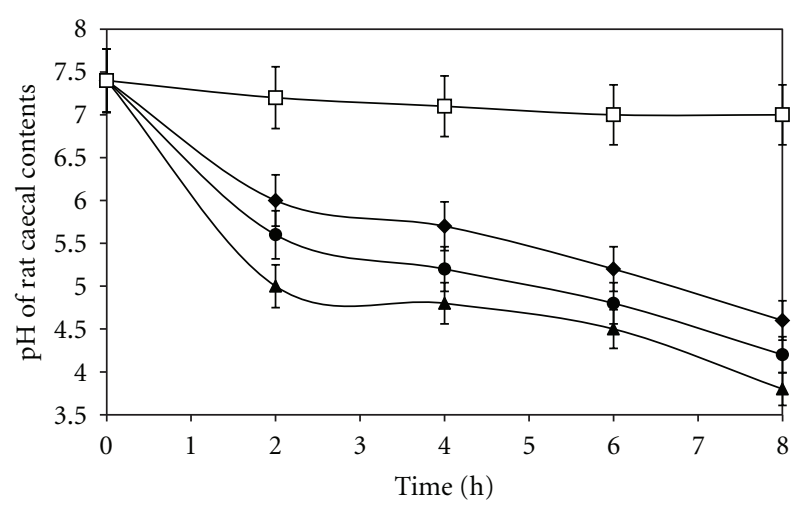

FIGURE 1: Changes of $\mathrm{pH}$ of phosphate buffer medium containing rat caecal content $(-) 4 \%,(-) 8 \%,(-) 12 \%$ with and without sterculia gum $(-)$. Each point represents the mean \pm SD.

samples was determined using a validated HPLC procedure as described by Shao-Jun et al. [27].

\subsection{Determination of Pharmacokinetic Parameters and Data} Analysis. Pharmacokinetic parameters were calculated by noncompartment analysis based on statistical moment theory using Microsoft Excel software. The pharmacokinetic parameters, such as maximum plasma concentration $\left(C_{\max }\right)$ and time of maximum concentration $\left(T_{\max }\right)$, were obtained directly from the plasma concentration-time plots. The area under the plasma concentration-time curve up to the last time $(t)\left(\mathrm{AUC}_{0-t}\right)$, area under curve extrapolated to infinity $\left(\mathrm{AUC}_{0-\infty}\right)$ and area under the first moment curve extrapolated to infinity $\left(\mathrm{AUMC}_{0-\infty}\right)$ were calculated using the linear trapezoidal rule. The mean residence time (MRT) was calculated as AUMC/AUC. Results were expressed as mean \pm standard deviation. Variations in pharmacokinetic parameters were tested using analysis of variance (ANOVA). In all the cases, a value of $P<0.05$ was considered statistically significant.

\section{Results and Discussion}

3.1. Microflora Degradation Studies of Sterculia Gum. Microflora degradation studies of sterculia gum revealed that the $\mathrm{pH}$ of caecal-PBS was decreased markedly from $\mathrm{pH} 7.4$ to 5.0 after incubation for $2 \mathrm{~h}$ with sterculia gum. The rate of decrease of $\mathrm{pH}$ was depended on the concentration of caecal contents within the $8 \mathrm{~h}$ of incubation (Figure 1). The decrease in $\mathrm{pH}$ was due to the appearance of degradation products of sterculia gum such as organic acids by the bacterial enzyme present in rat caecal contents.

3.2. Formulation Aspects of Core Tablets. The weight of each tablet was determined to be within the range of $240 \pm 5 \mathrm{mg}$ in order to maintain the relatively constant volume and surface area. The core tablet $(240 \mathrm{mg}$ each) was prepared at average tensile strength of $4.0 \mathrm{Kg} / \mathrm{cm}^{2}$ and average diameter of $8 \mathrm{~mm}$ and thickness $4 \mathrm{~mm}$. The incorporation of citric acid in the core composition increased the hydration of large amount of the gum and expanded its volume to great extent.

3.3. Evaluation of the Chitosan/Eudragit Coated Tablets. The weight variation was in the range of $275 \pm 2.09$ to $287 \pm$ $1.98 \mathrm{mg}$ and friability was less than $0.5 \%$. Uniformity in drug content was found among different batches of the tablet, and the drug content was more than $95 \%$.

3.4. Influence of Coating Formulation Variables on Drug Release. The core tablet was successfully coated by conventional pan coating technique with varying proportion of chitosan-eudragit RLPO provided by central composite design. The coating composition of the various formulations under $3^{2}$ factorial designs are presented in Table 2. The results of the in vitro dissolutions studies of different batches of coated tablets indicated that increase in concentration of chitosan from $15 \%$ to $25 \% \mathrm{w} / \mathrm{w}$ and keeping constant weight gain in thickness of polymers at $10 \% \mathrm{w} / \mathrm{w}$, the lag time (the time required for drug release up to $2 \%$ in SCF) was significantly decreased from $0.60 \mathrm{~h}$ to $0.25 \mathrm{~h}(\mathrm{FC} 1<\mathrm{FC} 4<$ FC7). The lag time was determined by separately running dissolution studies of chitosan/eudragit coated tablets in SCF for one hour at minimum time intervals. The amount of chitosan present in the eudragit coat was the key factor for such lag time. Lower amount of chitosan shows longer lag time, and higher amount shows shorter lag time.

3.5. Effects of Concentration of Chitosan on Drug Release. To study the effect of concentration of chitosan, its concentration in the coating solution was kept at $15 \% \mathrm{w} / \mathrm{w}$ for the batch FC1, 20\% w/w for FC4, and 25\% for FC7. The result of the in vitro release profile from these formulations is shown in Figure 2. It is observed that concentration of chitosan has direct effect on drug release. The formulation FC7 containing highest concentration $(25 \% \mathrm{w} / \mathrm{w})$ of chitosan in the coating composition released more than $90 \%$ of AZA after $18 \mathrm{~h}$ of the dissolution study. This might be due to the reason that an increased in the amount of chitosan (FC7 > FC4 > FC1), it became more susceptible to bacterial attack creating pores immediately resulting in shorter lag time $(0.15 \mathrm{~h})$ for drug release.

3.6. Effect of \% Weight Gain in Coating Thickness. It was observed that increased in the level of weight gain from $10 \%$, $12 \%$, and $14 \%$ in the batches of FC1, FC2, and FC3 and keeping the concentration of chitosan constant at $15 \% \mathrm{w} / \mathrm{w}$ made chitosan particles less susceptible to bacterial attack, resulting in longer lag time and lesser percentage of drug released in $18 \mathrm{~h}$ owing to less accessibility of the chitosan particles across the eudragit coat by the colonic bacteria. Figure 3 shows that as the coating thickness was increased, drug release was decreased, as evidenced by the difference factor $f 1$ value which was lower than 15 . For the calculation of $f 1$ and $f 2$ (similarity factor) values, only one data point at which more than $85 \%$ of the drug release had been released was taken into consideration. Drug release decreased. 
TABLE 2: Composition of the chitosan-eudragit RLPO film coating.

\begin{tabular}{|c|c|c|c|c|c|c|c|c|c|}
\hline \multirow{2}{*}{ Coating materials ( $\% \mathrm{w} / \mathrm{w})$} & \multicolumn{9}{|c|}{ Formulation code } \\
\hline & FC1 & $\mathrm{FC} 2$ & FC3 & FC4 & FC5 & FC6 & FC7 & FC8 & FC9 \\
\hline Micronized chitosan & 15 & 15 & 15 & 20 & 20 & 20 & 25 & 25 & 25 \\
\hline Eudragit RLPO & 60 & 60 & 60 & 55 & 55 & 55 & 50 & 50 & 50 \\
\hline PEG 400 & 25 & 25 & 25 & 25 & 25 & 25 & 25 & 25 & 25 \\
\hline Total weight & 100 & 100 & 100 & 100 & 100 & 100 & 100 & 100 & 100 \\
\hline$\%$ Weight gain in thickness & 10.0 & 12.0 & 14.0 & 10.0 & 12.0 & 14.0 & 10.0 & 12.0 & 14.0 \\
\hline
\end{tabular}

TABLE 3: ANOVA of dependent variables of chitosan/eudragit RLPO coated tablets.

\begin{tabular}{|c|c|c|c|c|c|}
\hline Sources of variation & Sum of squares & $D F$ & Mean square & $F$-ratio & $\begin{array}{c}\text { Prob }>F \\
P \text { value }\end{array}$ \\
\hline \multicolumn{6}{|l|}{$Y 1$ (lag time in SCF) } \\
\hline Regression & 0.23 & 5 & 0.046 & 212.17 & $<0.0001$ \\
\hline Residuals & 0.00 & 7 & 0.00 & & \\
\hline Total & 0.23 & 12 & 0.46 & & \\
\hline \multicolumn{6}{|l|}{$Y 2(\%$ rel in $12 \mathrm{~h})$} \\
\hline Regression & 389.68 & 2 & 194.84 & 116.67 & $<0.0001$ \\
\hline Residuals & 16.70 & 10 & 1.67 & & \\
\hline Total & 406.38 & 12 & & & \\
\hline \multicolumn{6}{|l|}{$Y 3(\%$ rel in $18 \mathrm{~h})$} \\
\hline Regression & 512.21 & 2 & 256.10 & 89.29 & $<0.0001$ \\
\hline Residuals & 28.68 & 10 & 2.87 & & \\
\hline Total & 540.89 & 12 & & & \\
\hline
\end{tabular}

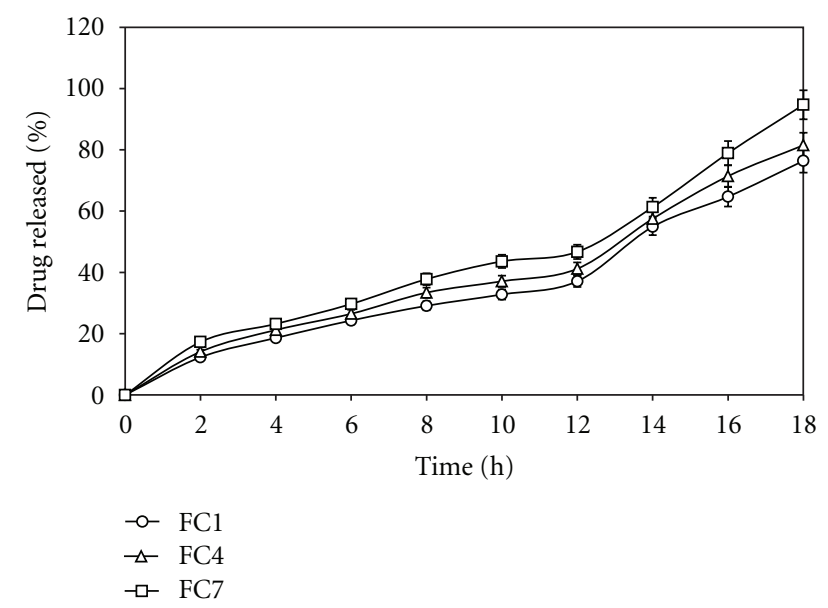

FIGURE 2: Effect of increasing concentration of pore former, chitosan (FC1-15\%) (FC4-20\%) and (FC7-25\%) on in vitro drug release in $\mathrm{SCF}$. Each point represents the mean \pm SD.

3.7. Statistical Analysis of Dissolution Data. ANOVA of the dependent variables indicated that the assumed regression models were significant $(P<0.0001)$ and valid for each considered response (Table 3 ). The response values of the coated tablets based on factorial design generated a mathematical model, which indicated that both the level of pore former and coating thickness had significant influence on percentage of drug release in the simulated colonic fluid at $\mathrm{pH}$ 7.4. The equations of the responses were found to be as follows:

$$
\begin{aligned}
Y_{1}= & 0.30-0.12 X_{1}+0.094 X_{2}+0.025 X_{1} X_{2} \\
& +0.069 X_{1}^{2}+0.019 X_{2}^{2} \\
Y_{2} & =47.91482+0.93240 X_{1}-2.5969 X_{2}, \\
Y_{3} & =72.42394+1.44879 X_{1}-1.69934 X_{2} .
\end{aligned}
$$

The above second-order polynomial equations represent the quantitative effects of independent variables $\left(X_{1}\right.$ and $\left.X_{2}\right)$ upon the responses $\left(Y_{1}, Y_{2}\right.$ and $\left.Y_{3}\right)$. The validity of the above equations was justified by substituting the values of $X_{1}$ and $X_{2}$ in (1) to obtain the predicted values of $Y_{1}, Y_{2}$, and $Y_{3}$. The observed and predicted values for the $Y_{2}$ response were found to be in good agreement (Table 4). The three-dimensional response surfaces plots were drawn to estimate the effects of the independent variables on each considered response (Figure 4).

3.8. Optimization of Chitosan-Eudragit RLPO Coating. The best colonic drug delivery system based on coating with microporous eudragit RLPO containing optimum amount of chitosan would be a system that could protect drug release in the higher parts of the small intestine and deliver the drug only at the colonic region. Chitosan particles in the RLPO coat remained undigested in the intestinal fluid due to 


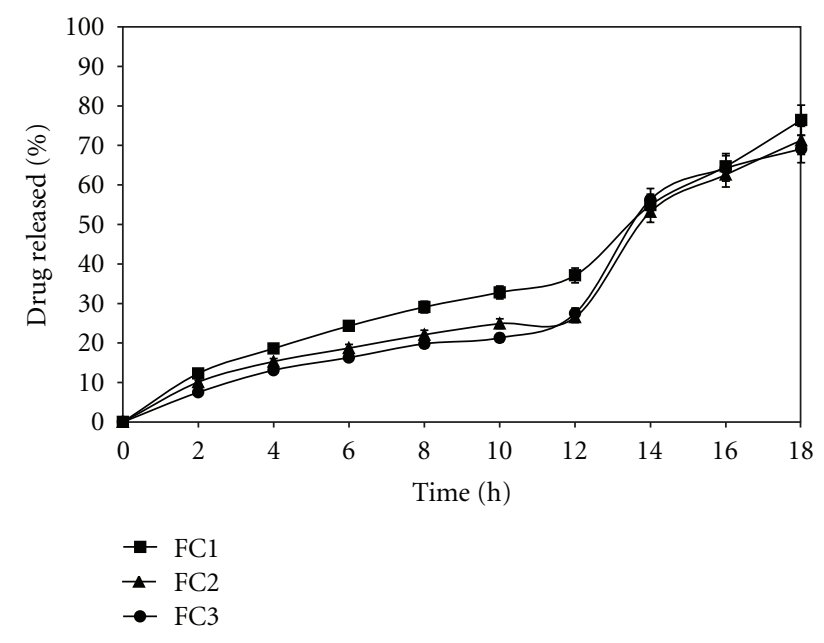

FIGURE 3: Effect of increasing coating thickness of eudragit RLPO (FC1-10\% w/w), (FC2-12\% w/w) and (FC3-14\% w/w) on in vitro drug release in SCF. Each point represents the mean \pm SD.

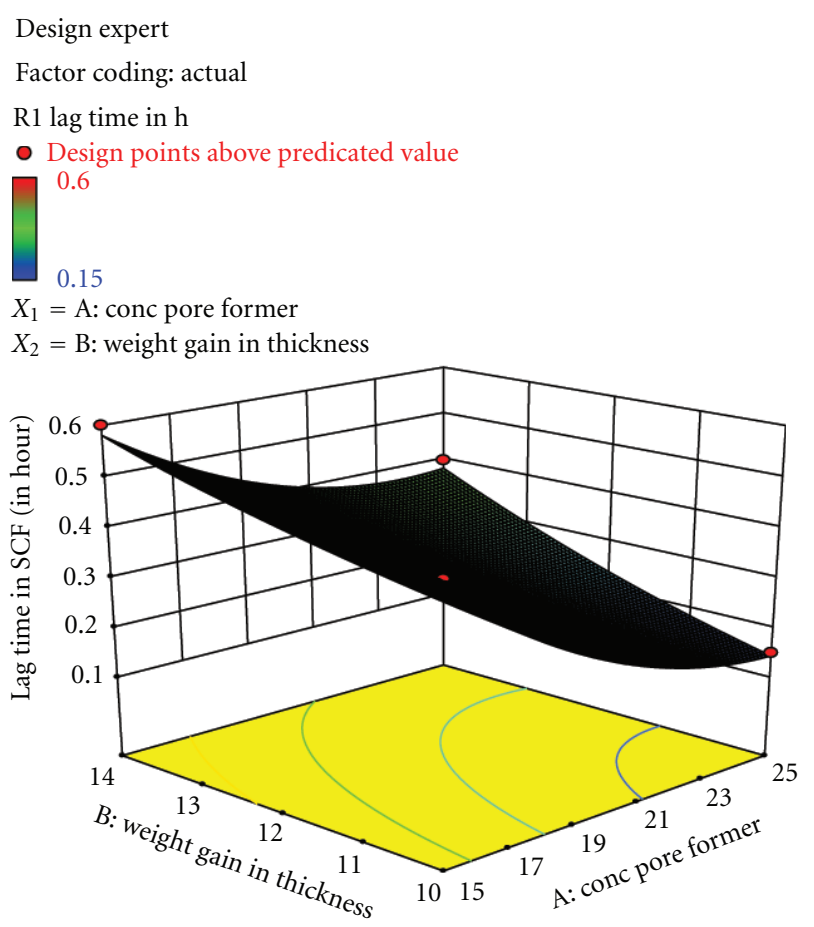

FIgURE 4: Response surface plot for response showing the influence of concentration of chitosan and \% weight gain in thickness on lag time.

absence of bacterial enzyme, but degraded in the colonic fluid due to the presence of vast anaerobic bacteria and allowed the drug release to occur. Therefore, the concentration of chitosan in the eudragit coat could be the key factor for lag time. The lag time was inversely related to the level of chitosan in the eudragit coat. The lag time in colonic environment $(\mathrm{pH}$ 7.4) was considered as response $Y_{1}$ and optimum duration for the response was considered to be 30 minutes. During this lag time, the chitosan in the eudragit coat comes in contact with

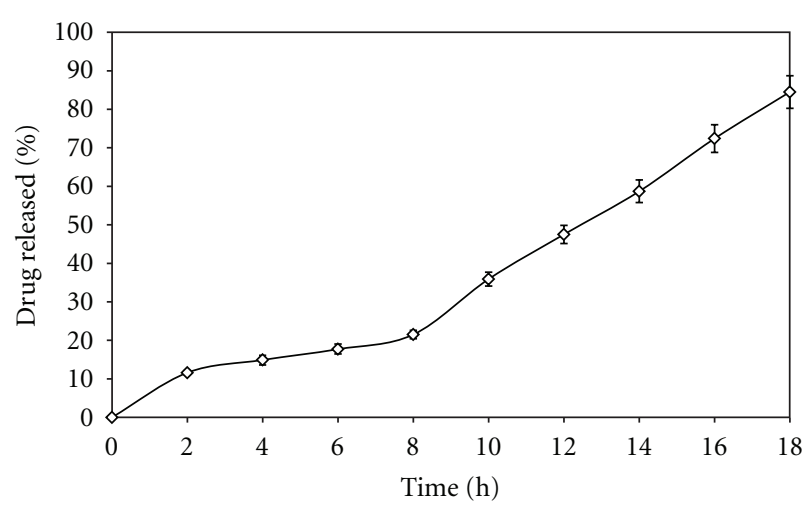

FIgURE 5: Dissolution rate profile of optimized chitosan-eudragit RLPO coated tablet in SCF.

the colonic bacteria formed in situ delivery pores for release of the drug. Thus, the percent of drug release in $12 \mathrm{~h}$ and $18 \mathrm{~h}$ was considered as response $Y_{2}$ and $Y_{3}$ with a constraint of minimum of $40 \%$ and $80 \%$ release, respectively. A suitable formulation which could meet these target responses would be able to release the maximum amount of drug in the colon despite its $2 \mathrm{~h}$ lag time in simulated gastric fluid (SGF, $0.1 \mathrm{M}$ $\mathrm{HCl}$ at $\mathrm{pH} 1.2$ containing $3.2 \mathrm{mg} / \mathrm{mL}$ pepsin) and $4 \mathrm{~h}$ lag time in simulated intestinal medium (SIF, phosphate buffer media at $\mathrm{pH} 6.8$ containing $5 \mathrm{mg} / \mathrm{mL}$ pancreatin).

The best formulation showing drug release corresponded to $18.96 \%$ of chitosan (pore former) and $11.3 \%$ of coating thickness of eudragit RLPO film provided the desired release as shown in Figure 5. The above quantity $\left(X_{1}\right.$ and $\left.X_{2}\right)$ of formulation was substituted in (1) to obtain the predicted responses. The validity of the optimization procedure was confirmed by preparing a new batch of coating formulation with the concentration provided by the software and the observed response were found to be inside the constraints and close to the predicted responses. Thus, the factorial design was valid for predicting the optimum formulation.

Results of in vitro dissolution study showed that the over coating with $10 \% \mathrm{w} / \mathrm{w}$ of enteric coating material (eudragit L100, dissolves above $\mathrm{pH}$ 6.0) provided the desired acid and intestinal resistance of the optimized chitosan-eudragit RLPO coated tablet. Figure 6 shows the in vitro release profile of optimized MCDDS in sequential phosphate buffer medium at different $\mathrm{pH}$ releasing more than $90 \%$ of the drug within $24 \mathrm{~h}$ duration.

3.9. Mechanism of Drug Release from MCDDS and Stability. Release kinetic data revealed that the optimized MCDDS was fitted well into first-order model and apparent lag time was found to be 6 hour, followed by higuchi spherical matrix release. It was evident that $r^{2}(0.9888)$ value was higher in first-order kinetic model as compared to the other release models. The reason for first-order kinetic release was due to the presence of enzyme degradable chitosan in the eudragit RLPO film which led to the formation of in situ orifices by bacterial enzyme and leaching out drug into the surrounding medium from the central polysaccharide 
TABLE 4: Predicted and observed value of experimental coating formulations.

\begin{tabular}{|c|c|c|c|c|c|}
\hline Coating formulations & Factor $X_{1}$ & Factor $X_{2}$ & Observed & Predicted & Residual \\
\hline $\mathrm{FC} 1$ & 15.00 & 10.00 & 37.10 & 35.99 & 1.11 \\
\hline FC2 & 12.93 & 12.00 & 26.50 & 28.88 & -2.38 \\
\hline FC3 & 15.00 & 14.00 & 27.50 & 25.63 & 1.87 \\
\hline FC4 & 20.00 & 9.17 & 41.20 & 42.7 & -1.5 \\
\hline FC5 & 20.00 & 12.00 & 35.60 & 35.47 & 0.13 \\
\hline FC6 & 20.00 & 14.83 & 27.80 & 28.14 & -0.34 \\
\hline FC7 & 25.00 & 14.00 & 38.70 & 32.81 & 5.89 \\
\hline FC8 & 27.07 & 12.00 & 41.70 & 42.05 & 0.35 \\
\hline FC9 & 25.00 & 10.00 & 46.70 & 44.50 & 2.20 \\
\hline
\end{tabular}

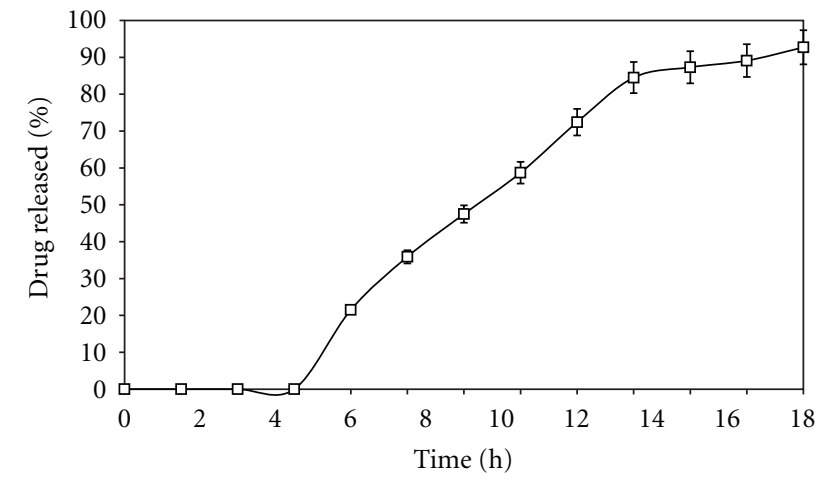

FIGURE 6: Dissolution rate profile of optimized MCDDS under continuous dissolution rate test in different media $(0-2 \mathrm{~h}$ in SGF at $\mathrm{pH} 1.2,2-6 \mathrm{~h}$ in SIF at $\mathrm{pH} 6.8$ and the rest of experiment in SCF at $\mathrm{pH} 7.4)$.

core tablet containing sterculia gum. When the majority of chitosan particle in the eudragit coat was degraded by colonic bacterial enzymes, it ruptured due to swelling pressure of the gum core and a gradual increase in drug release was observed, as swelling increases greater surface area of sterculia gum available for bacterial action. From the stability study, the developed MCDDS was found to bestable, because there was no significant change in the percentage drug content and hardness after six month of stability study stored at $40^{\circ} \mathrm{C} \pm$ $2^{\circ} \mathrm{C} / 75 \% \pm 5 \% \mathrm{RH}$.

3.10. HPLC Method Development. A novel simple, precise, selective, specific, reproducible, and low cost routine reverse phase HPLC method was developed and validated as per ICH guidelines. There were no such interfering peaks observed between the retention time of 6-MP and IS. A good resolution was obtained between 6-MP and IS with retention time of 7.88 minutes for 6-MP and 4.9 minutes for IS. The method was found to be linear $\left(r^{2}=0.999\right)$ within the analytical range of 53.32 to $4975.00 \mathrm{ng} / \mathrm{mL}$. Maximum recovery of the drug was obtained by using methanol: acetonitrile mixture $(1: 1)$. The results of the method validation were proved to be accurate and reproducible, and the drug was stable in rabbit plasma up to one month period at room temperature and at three freeze-thaw cycles.
TABLE 5: Comparison of pharmacokinetic parameters obtained after oral administration of three different formulations of AZA in rabbits with an equivalent dose of $50 \mathrm{mg} / \mathrm{Kg}$.

\begin{tabular}{lccc}
\hline $\begin{array}{l}\text { Pharmacokinetic } \\
\text { parameters }\end{array}$ & $\begin{array}{c}\text { MKT tablet } \\
\text { of AZA }\end{array}$ & $\begin{array}{c}\text { EC tablet of } \\
\text { AZA }\end{array}$ & MCDDS \\
\hline AUC $_{0-\infty}$ & 2130.76 & 2678.13 & 3380.41 \\
$C_{\max }(\mathrm{ng} / \mathrm{mL})$ & 1430.08 & 847.5 & 453.56 \\
$T_{\max }(\mathrm{h})$ & 1.50 & 5.00 & 9.00 \\
$\mathrm{Ke}\left(\mathrm{h}^{-1}\right)$ & 1.024 & 0.0911 & 0.0501 \\
$\left(t_{1 / 2}\right)^{\mathrm{e}}(\mathrm{h})$ & 0.6820 & 7.59 & 12.95 \\
$\mathrm{AUMC}$ & 7670.73 & 17729.22 & 46677.81 \\
$\mathrm{MRT}(\mathrm{h})$ & 3.60 & 6.62 & 13.81 \\
$\mathrm{Ka}\left(\mathrm{h}^{-1}\right)$ & 3.18 & 5.6 & 11.8 \\
$\left(t_{1 / 2}\right)^{\mathrm{a}}(\mathrm{h})$ & 0.2179 & 0.1239 & 0.0587 \\
$V_{d}(\mathrm{~L})$ & 2.26 & 7.80 & 12.71 \\
$\mathrm{TCR}(\mathrm{L} / \mathrm{h} / \mathrm{kg})$ & 2.31 & 0.7105 & 0.6367 \\
\hline
\end{tabular}

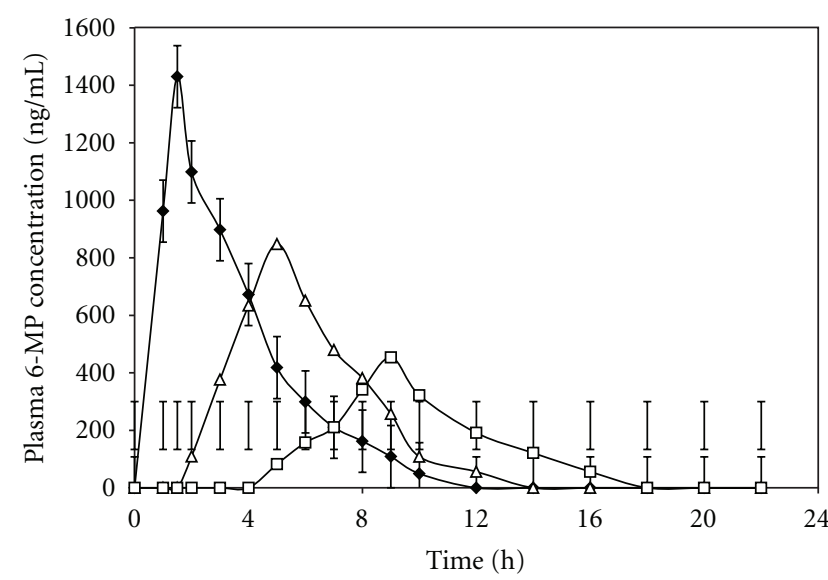

FIGURE 7: Comparison of mean plasma drug concentration versus time profile curve after oral administration of MKT tablet (-), EC tablet $(\triangle)$ and MCDDS $(-)$ of AZA in rabbit.

3.11. In Vivo Evaluation of MCDDS. Mean plasma 6-MP concentration versus time profiles after a single oral dose of MKT, EC, and MCDDS are depicted in Figure 7. Mean values of pharmacokinetic parameters are summarized in Table 5. 
In case of, MKT, the peak plasma concentration $\left(C_{\max }\right)$ of 6MP was obtained within $1.5 \mathrm{~h}$ of administration, indicating the immediate absorption of AZA from the gastrointestinal tract and quick conversion into its active metabolite, 6-MP in blood. The $C_{\max }$ value of 6-MP following oral administration of MKT tablet was found to be $1430.08 \mathrm{ng} / \mathrm{mL}$ at the time maximum $\left(T_{\max }\right)$ of $1.5 \mathrm{~h}$. The $C_{\max }$ value of $6-\mathrm{MP}$ for $\mathrm{EC}$ tablet of AZA without containing sterculia gum was found to be $847.5 \mathrm{ng} / \mathrm{mL}$ at $T_{\max }$ of $5.0 \mathrm{~h}$. From the results of in vitro release study, it was observed that the drug was released after $2.0 \mathrm{~h}$ of dissolution study which was quite desirable, due to the fact that the drug would be released from the tablets after passing the stomach region as the tablets were enteric coated. The results of in vivo studies of EC tablets showed that drug was not released in the stomach up to $2.0 \mathrm{~h}$ and therefore it gives $T_{\max }$ of $5.0 \mathrm{~h}$. Thus, the in vivo finding has good correlation with the in vitro results. A lag time of $6.0 \mathrm{~h}$ was observed from the MCDDS which revealed that the tablet had passed through the GIT and after reaching the colon only the drug was released and appeared in plasma as 6-MP. Therefore, the $C_{\max }$ value of 6-MP for the MCDDS could found to be $453.56 \mathrm{ng} / \mathrm{mL}$ at $T_{\text {max }}$ of $9.0 \mathrm{~h}$ after oral administration. The results of ANOVA revealed that there was significant difference of $\mathrm{AUC}_{0-\infty}$ between the MCDDS, $\mathrm{EC}$ and MKT formulation $(P<0.05)$. The results explained that the MKT formulation was more rapidly absorbed from the upper gastrointestinal tract of rabbit. But the EC and MCDDS were not absorbed from the upper GIT due to which they showed greater value of $\mathrm{AUC}_{0-\infty}$ as shown in the Table 5. It is evident that AUC for MCDDS was higher as compared to the reference formulation EC and MKT formulations (MCDDS $<\mathrm{EC}<\mathrm{MKT}$ ). Result suggests that the extent of absorption of AZA from the developed MCDDS was decreased from the large intestine, but increased from the upper part of the GIT as seen in case of EC and MKT formulation. From the in vivo studies, the $C_{\max }$ of MCDDS was found to be almost half of the EC tablet without containing sterculia gum. The longer $T_{\max }$ value $(9.0 \mathrm{~h})$ and low $C_{\max }$ value $(453.56 \mathrm{ng} / \mathrm{mL})$ of MCDDS as compared to the reference formulations had proved that the MCDDS released drug only at the colonic region of the rabbit intestine. This reveals localization of the drug in the colonic mucosa from the MCDDS and thereby, possibly reducing the risk of systemic toxicity.

\section{Conclusions}

Microflora degradation study revealed that sterculia gum can be used to release drug in the colonic region by utilizing the action of enterobacteria. The developed MCDDS exhibit gastric and small intestinal resistance but were susceptible to bacterial enzymatic attack and the potential of the system as a carrier for drug delivery to the colon is confirmed. The swelling property of sterculia gum can be used to produce hydrostatic pressure inside the tablet if it is coated with semipermeable membrane and can be used to target drug to the colon. Chitosan-eudragit RLPO mixed film coating provided the favourable characteristics to the sterculia gum core tablets to deliver it directly into the colon. Chitosan in the mixed film coat was found to be degraded by enzymatic action of the microflora in the colon. The degradation of chitosan was the rate-limiting factor for drug release in the colon. Drug release from the MCDDS was directly proportional to the concentration of chitosan, but inversely related to the weight gain in thickness of eudragit RLPO coat. The enteric layer of eudragit L100 could protect eudragit RLPO membrane containing chitosan from formation of pore or rupture before SCF dissolution procedure. Drug release from optimized MCDDS fitted well into first-order kinetic model followed by higuchi spherical matrix release model. The HPLC method developed shows good resolution to evaluate the pharmacokinetic parameters of the drug. Pharmacokinetic studies revealed that the MRT value $(13.81 \mathrm{~h})$ was higher for MCDDS as compared to the other two reference formulations, which were $3.60 \mathrm{~h}$ for MKT and $6.62 \mathrm{~h}$ for EC tablets, respectively. Finally, in vivo evaluation of MCDDS in rabbit showed delayed $T_{\text {max }}$, prolonged absorption time, decreased $C_{\max }$, and decreased absorption rate constant (Ka) indicating that drug was slowly absorbed from the colon making the drug available for local action in the colon, thereby, reducing the risk of systemic toxicity of the drug as compared to other dosage forms.

\section{References}

[1] A. Jain, Y. Gupta, and S. K. Jain, "Perspectives of biodegradable natural polysaccharides for site-specific drug delivery to the colon," Journal of Pharmacy and Pharmaceutical Sciences, vol. 10, no. 1, pp. 86-128, 2007.

[2] N. Pantel, J. Patel, T. Gandhi, and S. Shah, "Novel pharmaceutical approach for colon-specific drug delivery: an overview," Journal of Pharmacy Research, vol. 1, no. 1, pp. 2-10, 2008.

[3] Y. Z. Chang, H. Wei, F. Li et al., "Studies of chitosan/Kollicoat SR 30D film-coated tablets for colonic drug delivery," International Journal of Pharmaceutics, vol. 375, no. 1-2, pp. 8-15, 2009.

[4] K. Kwonho and K. Kaur, "Studies of chitosan/organic acid/ Eudragit; RS/RL-coated system for colonic delivery," International Journal of Pharmaceutics, vol. 366, no. 1-2, pp. 140-148, 2009.

[5] A. A. Chivate, S. S. Poddar, S. Abdul, and G. Savant, "Evaluation of Sterculia foetida gum as controlled release excipient," AAPS PharmSciTech, vol. 9, no. 1, pp. 197-204, 2008.

[6] M. M. Babu, C. S. Prasad, and K. V. Ramana Murthy, "Evaluation of modified gum karaya as carrier for the dissolution enhancement of poorly water-soluble drug nimodipine," International Journal of Pharmaceutics, vol. 234, no. 1-2, pp. 1-17, 2002.

[7] K. C. Waterman, B. C. MacDonald, and M. C. Roy, "Extrudable core system: development of a single-layer osmotic controlledrelease tablet," Journal of Controlled Release, vol. 134, no. 3, pp. 201-206, 2009.

[8] E. X. Lu, Z. Q. Jiang, Q. Z. Zhang, and X. G. Jiang, "A waterinsoluble drug monolithic osmotic tablet system utilizing gum arabic as an osmotic, suspending and expanding agent," Journal of Controlled Release, vol. 92, no. 3, pp. 375-382, 2003.

[9] J. W. McGinity, Aqueous Polymeric Coatings For Pharmaceutical Dosage Forms, Marcel Dekker, New York, NY, USA, 4th edition, 1997. 
[10] B. N. Singh and H. K. Kwon, "Characterization and relevance of physicochemical interactions among components of a novel multiparticulate formulation for colonic delivery," International Journal of Pharmaceutics, vol. 341, no. 1-2, pp. 143-151, 2007.

[11] W. J. Sandborn, H. Bonnie, B. Goldlust, and A. H. Goldberg, "Targeted delivery of azathioprine (AZA) to the ileum and colon for the treatment of Crohn's disease (CD): Scintigraphic and pharmacokinetic (PK) evaluation of a novel azathioprine delayed-release (AZA-DR) formulation," Gastroenterology, vol. 120, no. 5, pp. 625-629, 2001.

[12] M. Katsuma, S. K. Watanabe, and T. Hitoshi, "Studies on lactulose formulations for colon-specific drug delivery," International Journal of Pharmaceutics, vol. 249, no. 1-2, pp. 33-43, 2002.

[13] H. Zhang and S. H. Neau, "In vitro degradation of chitosan by bacterial enzymes from rat cecal and colonic contents," Biomaterials, vol. 23, no. 13, pp. 2761-2766, 2002.

[14] J. Varshosaz, N. Tavakoli, and F. Kheirolahi, "Use of hydrophilic natural gums in formulation of sustained-release matrix tablets of tramadol hydrochloride," AAPS PharmSciTech, vol. 7, no. 1, pp. E1-E7, 2006.

[15] S. U. Schilling, C. D. Bruce, N. H. Shah, A. W. Malick, and J. W. McGinity, "Citric acid monohydrate as a release-modifying agent in melt extruded matrix tablets," International Journal of Pharmaceutics, vol. 361, no. 1-2, pp. 158-168, 2008.

[16] P. Pandey, R. Turton, N. Joshi, E. Hammerman, and J. Ergun, "Scale-up of apan-coating process," AAPS PharmSciTech, vol. 7, no. 4, pp. E1-E8, 2006.

[17] A. Akhgari, F. Sadeghi, and H. A. Garekani, "Combination of time-dependent and $\mathrm{pH}$-dependent polymethacrylates as a single coating formulation for colonic delivery of indomethacin pellets," International Journal of Pharmaceutics, vol. 320, no. 12, pp. 137-142, 2006.

[18] H. Liu, X. G. Yang, S. F. Nie et al., "Chitosan-based controlled porosity osmotic pump for colon-specific delivery system: screening of formulation variables and in vitro investigation," International Journal of Pharmaceutics, vol. 332, no. 1-2, pp. 115-124, 2007.

[19] C. V. Raghavan, C. Muthulingam, J. A. J. L. Jenita, and T. K. Ravi, "An in Vitro and in Vivo investigation into the suitability of bacterially triggered delivery system for colon targeting," Chemical and Pharmaceutical Bulletin, vol. 50, no. 7, pp. 892-895, 2002.

[20] L. Yang, "Biorelevant dissolution testing of colon-specific delivery systems activated by colonic microflora," Journal of Controlled Release, vol. 125, no. 2, pp. 77-86, 2008.

[21] A. Kramar, S. Turk, and F. Vrečer, "Statistical optimisation of diclofenac sustained release pellets coated with polymethacrylic films," International Journal of Pharmaceutics, vol. 256, no. 1-2, pp. 43-52, 2003.

[22] N. Kotagale, M. Maniyar, S. Somvanshi, M. Umekar, and C. J. Patel, "Eudragit-S, Eudragit-L and cellulose acetate phthalate coated polysaccharide tablets for colonic targeted delivery of azathioprine," Pharmaceutical Development and Technology, vol. 15, no. 4, pp. 431-437, 2010.

[23] P. Costa and J. M. Sousa Lobo, "Modeling and comparison of dissolution profiles," European Journal of Pharmaceutical Sciences, vol. 13, no. 2, pp. 123-133, 2001.

[24] M. Marucci, G. Ragnarsson, U. Nyman, and A. Axelsson, "Mechanistic model for drug release during the lag phase from pellets coated with a semi-permeable membrane," Journal of Controlled Release, vol. 127, no. 1, pp. 31-40, 2008.
[25] J. T. Cartensen and C. T. Rhodes, Drug Stability, Principles and Practices, Informa Healthcare, New York, NY, USA, 3rd edition, 2010.

[26] M. L. Umrethia, P. K. Ghosh, R. J. Majithiya, and R. S. R. Murthy, "New RP-HPLC method for the estimation of 6mercaptopurine in rat plasma and various tissue homogenates," Journal of Liquid Chromatography and Related Technologies, vol. 29, no. 1, pp. 55-67, 2006.

[27] S. Shao-Jun, L. Zhong-Fang, C. Hua-Ting, and Z. Fan-Dian, "Pharmacokinetics and bioequivalence evaluation of azathioprine in healthy Chinese volunteers," Asian Journal of Pharmacodynamics and Pharmacokinetics, vol. 6, pp. 331-336, 2006.

[28] Y. Su, Y. Hon, Y. Chu, and M. V. Relling, "Assay of 6-MP and its metabolites in patient plasma by high performance liquid chromatography with diode-array detection," Journal of Chromatography and Biomedical Applications, vol. 732, no. 2, pp. 459-468, 1999.

[29] J. Tang, S. Zhou, L. Huang, Y. Huang, and H. Zhang, "Determination of azathiopurine and 6-mercaptopurine in serum by reversed-phase high performance liquid chromatography," International Journal of Pharmaceutics, vol. 16, no. 6, pp. 513-515, 1998. 

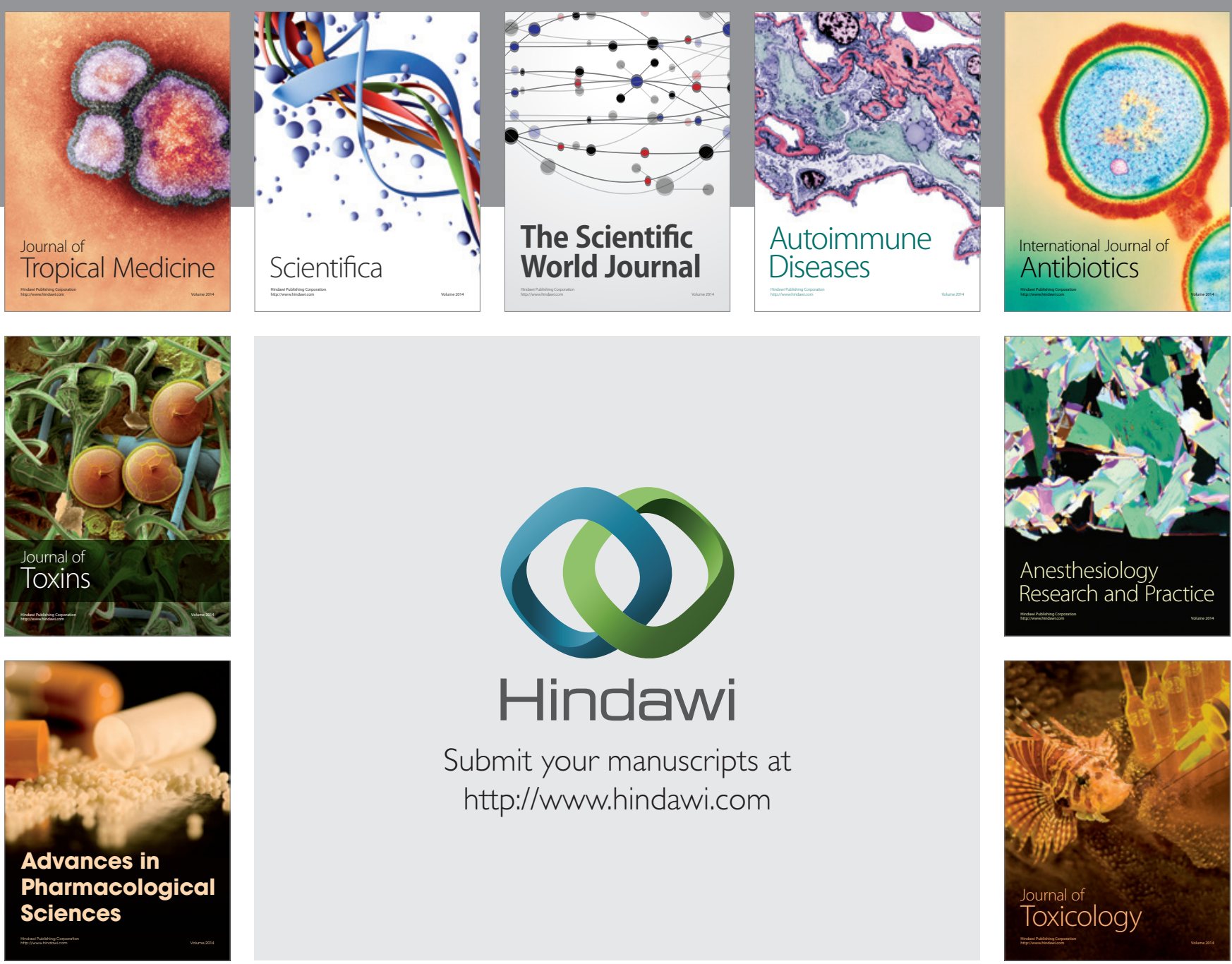

\section{Hindawi}

Submit your manuscripts at

http://www.hindawi.com
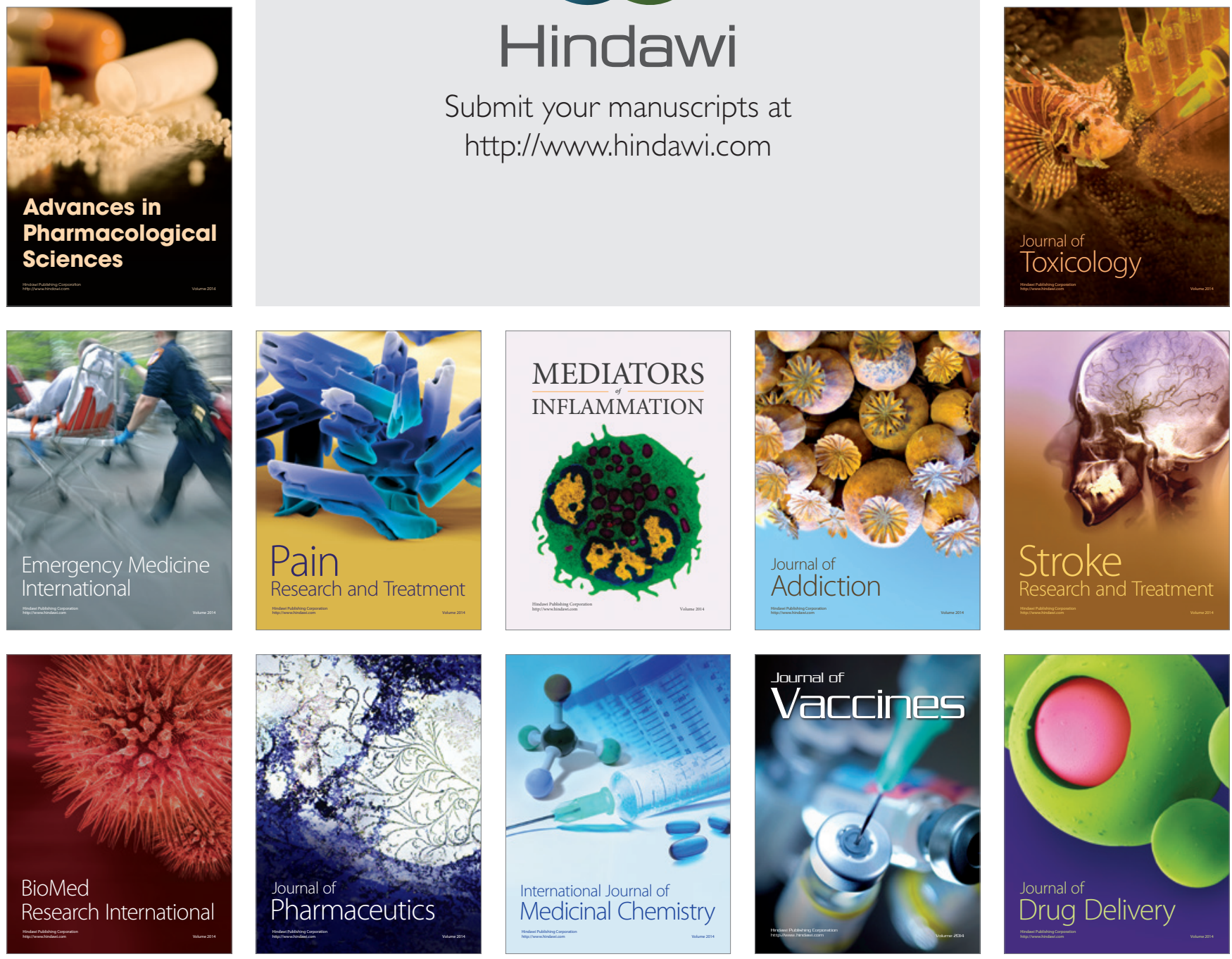